\title{
Prevalence of low birth weight babies and its association with socio-cultural and maternal risk factors among the institutional deliveries in Bharatpur, Nepal
}

\author{
Prerna Bansal' ${ }^{1}$, Sandeep Garg ${ }^{2}$, Hari Prasad Upadhyay ${ }^{3}$ \\ ${ }^{1}$ Consultant, Department of Community Medicine, College of Medical Sciences - Teaching Hospital, Bharatpur, \\ Chitwan, Nepal, ${ }^{2}$ Consultant, Department of Radio diagnosis, Chitwan Om Hospital, Bharatpur, Chitwan, Nepal, \\ ${ }^{3}$ Statistician, Department of Community Medicine, College of Medical Sciences - Teaching Hospital, Bharatpur, \\ Chitwan, Nepal
}

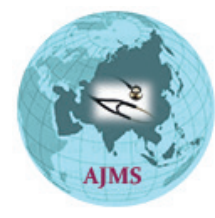

A B S T R A C T

Background: The low birth weight (LBW) is considered as sensitive index of nation's health and development. Almost a third of the newborn in the South East Asia region is low birth weight. Over three- quarters of newborn deaths in Nepal occur in low birth weight babies. The causes of low birth weight are multi-factorial and birth weight is determined by the interaction of both socio-demographic and biological factors. Aims and Objective: To find out the prevalence of low birth weight babies among institutional deliveries and its association with socio-cultural and maternal risk factors. Materials and Methods: A hospital based crosssectional study was undertaken comprising of 220 postnatal mothers along with singleton live born baby delivered in College of Medical Sciences and Teaching Hospital, Bharatpur, Nepal during the study period of April 2011 to March 2012. Binary logistic regression was used to find the association between dependent variable (LBW) and independent variables. Model accuracy test in binary logistic regression was done by using Hosmer and Lemeshow Test. To find the strength of binary logistic regression Pseudo R-square was used. Results: Out of 220 respondents, the prevalence of LBW was $23.6 \%$ (with $95 \% \mathrm{Cl} 21.88$ to $25.32 \%$ ). The risk factors like rest received in afternoon during pregnancy, dietary intake during pregnancy and period of gestation were found to be statistically significant. The odds of having LBW babies was 9.07 times higher in preterm births, 2.44 times higher among mothers who took afternoon rest of less than two hours and 3.44 times higher among those mothers who took dietary intake less or same as before during pregnancy. The variation in LBW due to these factors was found to be $22.9 \%$ to $34.4 \%$. Conclusion: The prevalence of low birth weight was found to be significantly high among institutional deliveries of this region of the country. Socio-cultural and maternal risk factors like rest received in the afternoon during pregnancy, dietary intake during pregnancy and period of gestation were found to be significantly associated with low birth weight babies. The problem of low birth weight babies can be lessened down as most of these factors can be tackled easily by providing adequate and effective antenatal care services with its maximum utilisation as well as home care by emphasising upon education of mothers and family members, hence decreasing infant and child mortality rates.

Key words: Low birth weight; Maternal risk factors; Period of gestation; Rest received in afternoon; Diet intake during pregnancy; Antenatal care

\section{Access this article online}

Website:

http://nepjol.info/index.php/AJMS DOI: 10.3126/ajms.v10i1.21665 E-ISSN: 2091-0576 P-ISSN: 2467-9100 


\section{INTRODUCTION}

Low birth weight is one of the most serious challenges in maternal and child health in both developed and developing countries. ${ }^{1}$ It is an essential determinant of mortality, morbidity and disability in infancy and childhood and also has a long-term impact on health outcomes in adult life. ${ }^{2}$ It is a reliable indicator in monitoring and evaluating the success of maternal and child health programmes. ${ }^{3}$ The low birth weight is considered as sensitive index of nation's health and development. ${ }^{4}$

By international agreement " $\mathrm{A}$ low birth weight baby is one with a birth weight less than $2.5 \mathrm{~kg}$ (up to and including $2499 \mathrm{~g}$ ), the measurement being taken preferably within first hour of life, before significant postnatal weight loss has occurred. ${ }^{1}$

LBW is a multifaceted problem that may result in a wide spectrum of diseases in later life such as hypertension, ischemic heart disease, stroke, metabolic syndrome, diabetes, malignancies, osteoarthritis and dementia. ${ }^{5} \mathrm{LBW}$ babies are at an increased risk of asphyxia, hypoglycaemia, polycythemia-hyper viscosity and hypothermia. ${ }^{6}$ Low birth weight infants are also at increased risk of long-term disability and impaired development like delayed motor and social development. LBW also increases a child's likelihood of having a school-age learning disability, being enrolled in special education classes, having a lower IQ, and dropping out of high school. Being born with a low birth weight also incurs enormous economic costs, including higher medical expenditures, special education and social service expenses, and decreased productivity in adulthood. ${ }^{7}$

WHO estimates that globally about 25 million low birth weight babies are born each year, consisting $14 \%$ of all live births, nearly 93\% of them in developing countries. Southern Asia is the region with highest incidence (27\%), whereas $14 \%$ in Africa, 9\% in Latin America and Caribbean and 6\% in Eastern Asia (countries like China, Japan, North Korea and South Korea). ${ }^{1}$ Asia has the lowest mean birth weight babies in the world. Almost a third of the newborn in the South East Asia region is low birth weight. ${ }^{6}$ In Nepal, the percentage of newborns with low birth weight $(<2.5 \mathrm{~kg})$ is $11 \%$ at national level and ranges from 15.4\% to $6.9 \%$ in different provinces of the country. ${ }^{8}$ Over three-quarters of newborn deaths in Nepal occur in low birth weight babies. ${ }^{9}$ One of the important causes of protein energy malnutrition in Nepal is low birth weight of below $2.5 \mathrm{~kg}$, a sign of poor maternal nutrition, inadequate dietary intake, frequent infections, household food insecurity, feeding behaviour and poor care and practices. This leads to an intergenerational cycle of malnutrition which constitutes a serious threat especially to young child survival and is associated with one third of child mortality. ${ }^{10}$
It is estimated that the risk of neonatal mortality for LBW infants is 25 to 30 times more than for infants with birth weight exceeding 2500 grams, and it increases sharply as birth weight decreases. ${ }^{11,12}$ Studies in Nepal also has supported this negative association by reporting early childhood mortality rates to be nearly 2 times higher in small or very small size babies at birth as compared to average or large size babies at birth. It was also stated that the size at birth is an important indicator of the nutritional status of children of our country as stunting is higher among children who were reported to have been small at birth $(60 \%)$ than among children who were average or larger in size at birth (47\%). ${ }^{13}$

The causes of LBW are multi-factorial and birth weight is determined by the interaction of both socio-demographic and biological factors. ${ }^{14,15}$ Low birth weight in developing countries occurs primarily because of poor maternal health and nutrition. ${ }^{16-19}$ Low birth weight which is related to maternal malnutrition, is a causal factor in 60-80 per cent of neonatal deaths. ${ }^{20} \mathrm{~A}$ study has identified 43 potential factors for low birth weight, ${ }^{15}$ not that all the factors, should be present in a given area. Also prevalence of LBW, mean birth weight and factors shows a degree of variation from country to country and area to area within the same country depending upon geographic, socioeconomic and cultural factors. Thus it is necessary to identify factors prevailing in a particular area responsible for low birth weight, so as to plan the strategy to tackle accordingly.

Therefore the objective of present study is to find out the prevalence of low birth weight babies and its association with socio-cultural and maternal risk factors in this region, so that it will be helpful for improving health policies and programmes to address this important health problem.

\section{MATERIALS AND METHODS}

A hospital based cross-sectional study was conducted among postnatal mothers along with singleton live born baby delivered at College of Medical Sciences and Teaching Hospital, Bharatpur during the study period of April 2011 to March 2012. Sample size was determined by using the formula $n=\left(z^{2} \times p q\right) / e^{2}$. The proportion of low birth weight in central Nepal was taken as $9 \%{ }^{21}$ so, $p=0.09$ and $q=0.91$. The $z$-score value at $5 \%$ level of significance for two tail test is 1.96 with standard error $4 \%$, the required sample size of this study was 220 (including $10 \%$ of the sample size for the accuracy). Simple random sampling technique was used to collect the data. The total of 220 postnatal mothers who were admitted in the postnatal wards of College of Medical Sciences during the study duration were enrolled in the study. Ethical approval was 
taken from Ethical Committee of College of Medical Sciences and written informed consent was taken from all the respondents. Questionnaire method was used to collect the data from the patients.

The collected data was first checked for completeness and consistency. Different socio-cultural and maternal variables were coded and entered in to the SPSS version 20 software. The entered data were cleaned and edited before subsequent analysis. Both descriptive and inferential statistics were used in the analysis. In descriptive statistics mean and standard deviation were computed for low birth weight, also pie-chart and bar diagram were used to show the results.

Proportion of low birth weight was determined first and LBW proportion associated with each factors was computed by chi-square test and fisher exact test. The variable which are statistically significant in cross tabulation, were selected for the further analysis. Binary logistic regression was used to show the relationship between independent and dependent variable of low birth weight. The variables used in the study were maternal age, education of mother, religion, type of family, family income, place of residence, family size, period of gestation, sex of child, mother age at first conception, mother's age at marriage, rest received in the afternoon during pregnancy, number of ANC visits, iron and folic acid tablets consumption, anaemia, height of mother and dietary intake during pregnancy.

\section{RESULTS}

A total of 220 respondents were included in the study in which $15.5 \%$ were aged below 20 years, $81.8 \%$ between 20 34 years and $2.7 \%$ were above 35 years. The percentage of respondent's age at first conception greater than or equal to 18 years was $88.2 \%$. Most of the respondents were literate, only $3.6 \%$ of them were illiterate. $64.55 \%$ were from joint family and remaining $(35.45 \%)$ were from nuclear family. $64.55 \%$ were from rural and remaining from urban areas. $87.2 \%$ of the respondents visited the health institution greater than or equal to four times. Only $51.82 \%$ of the respondent took afternoon rest greater than or equal to two hours during pregnancy. Among the total delivery $79.10 \%$ were term delivery and $20.90 \%$ were preterm. $95.45 \%$ of the respondents had taken iron and folic acid tablets during the pregnancy. Also, $79.54 \%$ of the respondent's monthly income was less than 20,000 NRs. $85.5 \%$ of the respondent belonged to Hindu religion and remaining were of other religions. Among the total children born in the hospital during the study period, $51.18 \%$ were males and $41.82 \%$ were females (Table 1).

The prevalence of low birth weight was 23.6\% (with 95\% CI 21.88 to $25.32 \%$ ) (Table 2, Figure 1). The overall mean birth weight found was $2.79 \pm 0.588 \mathrm{~kg}$. Out of low birth weight babies, the mean of birth weight was $1.99 \pm 0.481 \mathrm{~kg}$.

Among all the deliveries $20.90 \%$ of the respondents had preterm delivery (with 95\% CI 19.25 to $22.55 \%$ ). Likewise $48.18 \%$ respondents took less than 2 hours rest in the

\begin{tabular}{|c|c|c|}
\hline Characteristics & Frequency & Percentage \\
\hline \multicolumn{3}{|l|}{ Age of mother } \\
\hline$<20$ years & 34 & 15.5 \\
\hline $20-34$ years & 180 & 81.8 \\
\hline$\geq 35$ years & 6 & 2.7 \\
\hline Mean $\pm S D$ & $23.75 \pm 4.36$ & \\
\hline \multicolumn{3}{|l|}{ Age of mother at first } \\
\hline conception & 26 & 11.8 \\
\hline$<18$ years & 194 & 88.2 \\
\hline$\geq 18$ years & $21.37 \pm 3.57$ & \\
\hline Mean $\pm S D$ & & \\
\hline \multicolumn{3}{|l|}{ Education of mother } \\
\hline Literate & 212 & 96.4 \\
\hline Illiterate & 8 & 3.6 \\
\hline \multicolumn{3}{|l|}{ Family type } \\
\hline Nuclear & 78 & 35.45 \\
\hline Joint & 142 & 64.55 \\
\hline \multicolumn{3}{|l|}{ ANC visit } \\
\hline Adequate $(\geq 4)$ & 192 & 87.27 \\
\hline Inadequate $(<4)$ & 28 & 12.73 \\
\hline \multicolumn{3}{|l|}{ Place of residence } \\
\hline Urban & 78 & 35.45 \\
\hline Rural & 142 & 64.55 \\
\hline \multicolumn{3}{|l|}{ Rest received in the } \\
\hline afternoon & 106 & 48.18 \\
\hline$<2$ hour & 114 & 51.82 \\
\hline \multirow{2}{*}{\multicolumn{3}{|c|}{ Period of gestation }} \\
\hline & & \\
\hline Preterm & 46 & 20.90 \\
\hline Term & 174 & 79.10 \\
\hline \multicolumn{3}{|c|}{ Iron and Folic acid tablets } \\
\hline consumption & 210 & 95.45 \\
\hline Yes & 10 & 4.54 \\
\hline \multicolumn{3}{|l|}{ No } \\
\hline \multicolumn{3}{|l|}{ Family income } \\
\hline$<20,000$ & 175 & 79.54 \\
\hline $20,000-40,000$ & 36 & 16.36 \\
\hline$\geq 40,000$ & 9 & 4.01 \\
\hline \multicolumn{3}{|l|}{ Religion } \\
\hline Hindu & 188 & 85.5 \\
\hline Other than Hindu & 32 & 14.5 \\
\hline \multicolumn{3}{|l|}{ Sex of child } \\
\hline Male & 128 & 58.18 \\
\hline Female & 92 & 41.82 \\
\hline
\end{tabular}

\begin{tabular}{|c|c|c|}
\hline Characteristics & n (\%) & $95 \% \mathrm{Cl}$ \\
\hline Low Birth weight (LBW) & $52(23.6)$ & (21.88 to 25.32 ) \\
\hline Preterm delivery & $46(20.90)$ & (19.25 to 22.55 ) \\
\hline $\begin{array}{l}\text { Rest received in the } \\
\text { afternoon }(<2 \text { hrs.) }\end{array}$ & $106(48.18)$ & (46.15 to 50.21$)$ \\
\hline $\begin{array}{l}\text { Iron and folic acid } \\
\text { tablets consumed }\end{array}$ & $210(95.45)$ & (94.60 to 96.30$)$ \\
\hline Smoking habit & $12(5.5)$ & (4.58 to 6.42$)$ \\
\hline
\end{tabular}




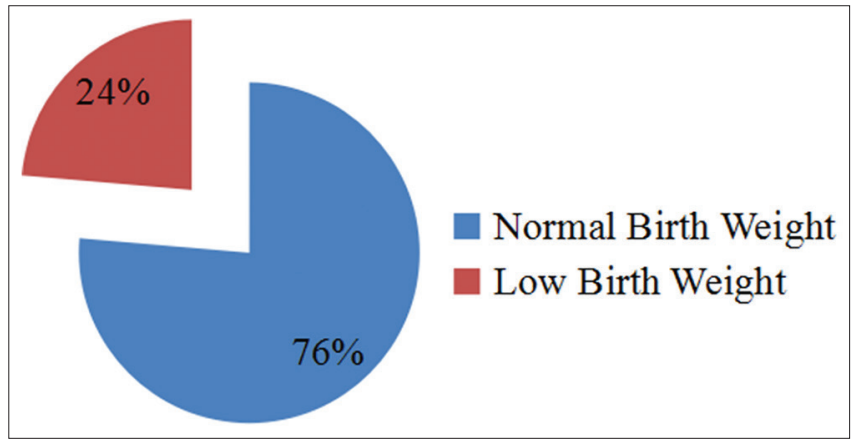

Figure 1: Prevalence of Low Birth Weight afternoon during pregnancy with $95 \%$ CI (46.15 to 50.21). Almost all (95.45\%) respondents received iron and folic acid tablets with 95\% CI (94.60 to 96.30) and 5.50\% had habit of smoking with $95 \%$ CI (4.58 to 6.42) (Table 2).

To find the risk factors associated with low birth weight chi-square and fisher exact test were used for analysis which showed that three variables: rest received in afternoon during pregnancy ( $\mathrm{p}$-value $<0.05$ ), period of gestation $(\mathrm{p}$-value $<0.05)$ and dietary intake during pregnancy $(\mathrm{p}$-value $<0.05)$ were statistically significant with LBW (Table 3).

Table 3: Association between low birth weight and different variables $(n=220)$

\begin{tabular}{|c|c|c|c|c|}
\hline Characteristics & Number & LBW n (\%) & Chi-square & P-value \\
\hline \multicolumn{5}{|l|}{ Age of mother (in years) } \\
\hline$<20$ and $\geq 30$ & 59 & $17(28.8)$ & 1.197 & 0.274 \\
\hline $20-29$ & 161 & $35(21.7)$ & & \\
\hline \multicolumn{5}{|l|}{ Education of mother } \\
\hline Illiterate & 8 & $3(37.5)$ & 0.884 & $0.397^{a}$ \\
\hline Literate & 212 & $49(23.1)$ & & \\
\hline \multicolumn{5}{|l|}{ Family size } \\
\hline$\geq 5$ & 86 & $21(24.4)$ & & \\
\hline \multicolumn{5}{|l|}{ Family type } \\
\hline Nuclear & 78 & $19(24.4)$ & 0.035 & 0.827 \\
\hline Joint & 142 & $33(23.2)$ & & \\
\hline \multicolumn{5}{|l|}{ ANC visit } \\
\hline Adequate & 28 & $12(42.9)$ & 0.579 & 0.447 \\
\hline Inadequate & 192 & $40(20.8)$ & & \\
\hline \multicolumn{5}{|l|}{ Place of residence } \\
\hline Urban & 78 & $14(17.9)$ & & \\
\hline \multicolumn{5}{|l|}{ Rest received in the afternoon } \\
\hline$<2$ hour & 106 & $36(34)$ & 12.084 & $0.001^{*}$ \\
\hline$\geq 2$ hour & 114 & $16(14)$ & & \\
\hline \multicolumn{5}{|l|}{ Period of gestation } \\
\hline Preterm & 46 & 28(60.9) & 44.671 & $<0.001^{*}$ \\
\hline Term & 174 & $24(13.8)$ & & \\
\hline \multicolumn{5}{|l|}{ Anaemia } \\
\hline Anaemic & 75 & $20(26.7)$ & 0.579 & 0.447 \\
\hline Normal $\mathrm{Hb}$ & 145 & $32(22.1)$ & & \\
\hline \multicolumn{5}{|c|}{ Iron and Folic acid tablet consumption } \\
\hline Yes & 210 & $49(23.3)$ & 0.235 & 0.628 \\
\hline No & 10 & $3(30)$ & & \\
\hline \multicolumn{5}{|l|}{ Family income } \\
\hline$<20,000$ & 175 & $43(24.6)$ & 1.530 & 0.456 \\
\hline $20,000-40,000$ & 36 & $8(22.1)$ & & \\
\hline$<18$ & 56 & $17(30.4)$ & 1.880 & 0.170 \\
\hline$\geq 18$ & 164 & $35(21.3)$ & & \\
\hline \multicolumn{5}{|l|}{ Sex of child } \\
\hline Male & 128 & $31(24.2)$ & 0.058 & 0.810 \\
\hline Female & $92^{\prime}$ & $21(22.8)$ & & \\
\hline \multicolumn{5}{|c|}{ Dietary intake during present pregnancy } \\
\hline Less than/ same as before & 58 & $25(43.1)$ & 3.788 & $<0.001^{*}$ \\
\hline More than before & 162 & $27(16.71)$ & & \\
\hline \multicolumn{5}{|l|}{ Height of mother } \\
\hline$<145 \mathrm{~cm}$ & 5 & 3(60) & 3.748 & $0.087^{a}$ \\
\hline$\geq 145 \mathrm{~cm}$ & 215 & $49(22.8)$ & & \\
\hline
\end{tabular}

*Statically significant at $<0.05$, a value obtained from fisher exact test 
Test of multicollinearity

The presences of multicollinearity within the set of independent variables were determined by using variance inflation factor. Here all variance inflation factors were less than ten so, there does not exist multicollinearity between independents variables (Table 4).

\section{Binary logistic regression}

The statistically significant variables from cross tabulation were taken for the further analysis. To find the net effect of each independent variable Binary logistic regression were used.

The odds of low birth weight children were higher among those mothers who had preterm deliveries $(\mathrm{OR}=9.078$, with $95 \%$ CI 4.148 to 19.869 ), this result found to be statistically significant $(\mathrm{p}$-value $=<0.001)$. In the same manner mother who took less than two hours rest in the afternoon during pregnancy have higher odds of low birth

\begin{tabular}{lcc}
\hline Table 4: Test of multicollinearity & \multicolumn{2}{c}{ Collinearity statistics } \\
\hline & $\begin{array}{c}\text { Variance } \\
\text { Chflation factors }\end{array}$ & Tolerance \\
\hline $\begin{array}{l}\text { Rest received in } \\
\text { the afternoon }\end{array}$ & 1.042 & 0.96 \\
$\begin{array}{l}\text { Period of gestation } \\
\text { Diet intake during } \\
\text { present pregnancy }\end{array}$ & 1.03 & 0.971 \\
\hline
\end{tabular}

weight as compare to rest received more than two hours in the afternoon during pregnancy $(\mathrm{OR}=2.446$, with $95 \%$ CI 1.156 to 5.178$)$. This result was found to be statistically significant $(p$-value $=0.019)$. Similarly, mother who took the dietary intake same or less than before during pregnancy have higher odds as compared to dietary intake more than before $(\mathrm{OR}=3.441$, with $95 \%$ CI 1.599 to 7.405$)$. This result was also found to be statistically significant ( $\mathrm{p}$-value $=0.002$ ) (Table 5).

\section{Model adequacy test}

For the model adequacy test in the binary logistic regression Hosmer and Lemeshow Test was used. For this test a model is said to be poor fit if the P-value is less than 0.05 . Here for low birth weight chi-square value is 0.327 with 5 degree of freedom and P-value is 0.997, which implies that there is no significant difference between observed and predicted values indicating that model fit the data at an acceptable level (Table 6).

\section{Pseudo R-square value}

The strength of logistic regression is computed from the pseudo R-square value. In the logistic regression model the indication of the amount of variation in the dependent variable is given by Cox \& Snell R Square and Nagelkerker R Square which described as Pseudo $\mathrm{R}$-Square. The result in the below table reveals that the value are 0.229 and 0.334 respectively suggesting that between $22.9 \%$ and $34.4 \%$ variation in response variable

\section{Table 5: Logistic regression of low birth weight for different characteristics}

\begin{tabular}{|c|c|c|c|c|c|c|}
\hline \multirow[t]{2}{*}{ Characteristics } & \multirow[t]{2}{*}{ B } & \multirow[t]{2}{*}{ d.f } & \multirow[t]{2}{*}{$\mathrm{P}$-value } & \multirow[t]{2}{*}{ OR } & \multicolumn{2}{|c|}{$95 \% \mathrm{Cl}$ for OR } \\
\hline & & & & & Lower & Upper \\
\hline $\begin{array}{l}\text { Period of gestation } \\
\text { Term } \\
\text { Preterm }\end{array}$ & 2.206 & 1 & $<0.001$ & 9.078 & 4.148 & 19.869 \\
\hline $\begin{array}{l}\text { Rest received in the afternoon } \\
\geq 2 \\
<2\end{array}$ & 0.2 .446 & 1 & 0.019 & 2.446 & 1.156 & 5.178 \\
\hline $\begin{array}{l}\text { Dietary intake during present pregnancy } \\
\text { More than before } \\
\text { Less than/ same as before }\end{array}$ & 1.236 & 1 & 0.002 & 3.441 & 1.599 & 7.405 \\
\hline
\end{tabular}

\section{Table 6: Contingency table for hosmer and lemeshow test}

\begin{tabular}{|c|c|c|c|c|c|c|c|}
\hline \multicolumn{2}{|c|}{ Low birth weight } & \multicolumn{2}{|c|}{ Normal birth weight } & \multirow[t]{2}{*}{ Total } & \multirow[t]{2}{*}{$\chi^{2}$} & \multirow[t]{2}{*}{ d.f } & \multirow[t]{2}{*}{ P-value } \\
\hline Observed & Expected & Observed & Expected & & & & \\
\hline 13 & 13.564 & 4 & 3.436 & 17 & 0.327 & 5 & 0.997 \\
\hline 10 & 9.542 & 6 & 6.458 & 16 & & & \\
\hline 5 & 4.895 & 8 & 8.105 & 13 & & & \\
\hline 8 & 7.897 & 14 & 14.103 & 22 & & & \\
\hline 4 & 3.539 & 15 & 15.461 & 19 & & & \\
\hline 7 & 7.698 & 48 & 47.302 & 55 & & & \\
\hline 5 & 4.865 & 73 & 73.135 & 78 & & & \\
\hline
\end{tabular}




$\begin{aligned} & \text { Table 7: Pseudo R-square table for low birth } \\
& \text { weight }\end{aligned}$
\begin{tabular}{lcc}
\hline -2 Log likelihood & $\begin{array}{c}\text { Cox \& Snell } \\
\text { R square }\end{array}$ & $\begin{array}{c}\text { Nagelkerke } \\
\text { R square }\end{array}$ \\
\hline 183.418 & 0.229 & 0.344 \\
\hline
\end{tabular}

is explained by the set of independent variables used in the model (Table 7).

\section{DISCUSSION}

In the present study the prevalence of low birth weight was found to be $23.6 \%$ (with $95 \%$ CI 21.88 to $25.32 \%$ ). Two other studies by $\mathrm{Mondol}^{22}$ in Meghalaya, India and Yadav et al., ${ }^{23}$ in Janakpur, Nepal showed similar percentage of LBW of $21.53 \%$ and $21.56 \%$ respectively. On the other hand other studies like NDHS (2011) ${ }^{21}$, Singh et al., Kayastha et al., ${ }^{24}$ Roudbari et al., ${ }^{25}$ Yilgwan et al., ${ }^{26}$ Khorshidi et al., ${ }^{27}$ Badshah et al., ${ }^{28}$ and Paneretto et al., ${ }^{29}$ found lower percentage of low birth weight as $12 \%, 11.07 \%, 11.9 \%$, $11.8 \%, 12.7 \%, 2.9 \%$ (CI $95 \%: 2.3$ to 3.3 ), $9.9 \%$ and $11.1 \%$ respectively. In our study the overall mean birth weight found was $2.79 \pm 0.588 \mathrm{~kg}$ and among LBW babies the mean birth weight was $1.99 \pm 0.481 \mathrm{~kg}$. Similarly, Yadav et al., found overall mean birth weight of $2.75 \pm 0.639 \mathrm{~kg}$ and the mean birth weight among LBW newborns of 1.96 $\pm 0.409 \mathrm{~kg} .{ }^{23}$ Whereas, higher mean birth weight was found by i.e. Yilgwan et al., ${ }^{26}$ as $3.08 \pm 1.319 \mathrm{~kg}$ and Panaretto et al., ${ }^{29}$ as $3.239 \mathrm{~kg}$.

In our study, the maximum number of mothers $(81.8 \%)$ belonged to age group 20-30 years. The mean age of mothers was $23.75 \pm 0.4 .36$ years. The proportion of low birth weight babies was more in $<20$ and $\geq 30$ years $(28.8 \%)$ as compared to $20-29$ years age group of mothers $(21.7 \%)$. A significant association was not found between mother's age and birth weight of babies. Similarly, Yadav et al.,also found that LBW babies mostly (31\%) from mothers of $<19$ and $\geq 30$ years age group while minimum (17\%) LBW babies delivered from mothers of $20-29$ years age group. ${ }^{23}$ NDHS (2011) found LBW higher (13.4\%) among younger mothers ( $<20$ years) than among mothers of age $20-34$ years $(12.1 \%)$ and $12.3 \%$ among mothers of age 35-49 years. ${ }^{21}$ Other studies by Rana ${ }^{30}$, Roudbari et al., ${ }^{25}$ Anand et al., ${ }^{31} \mathrm{Krammer}^{15}$, Yilgwan et al., ${ }^{26}$ Kayastha et al., ${ }^{24}$ and Singh et al., ${ }^{6}$ also did not find statistical significance between mother's age and low birth weight babies. Whereas Badshah et al., ${ }^{28} \mathrm{Mondol}^{22}$ and Ezechi et al., ${ }^{32}$ found significant association of maternal age with low birth weight babies.

Also in our study the percentage of low birth weight babies was higher among illiterate mothers $(37.5 \%)$ than literate mothers $(23.1 \%)$. A significant association was not found between mother's education and birth weight of babies. Similarly, Mondol ${ }^{22}$, Roudbari et al., ${ }^{25}$ and Yadav et al., ${ }^{23}$ also found higher percentage of low birth weight among illiterate mothers. Anand et al., ${ }^{31}$, Joshi et al., ${ }^{33}$ and NDHS (2011) ${ }^{21}$ also identified that lower maternal education was significantly associated with risk of LBW. Kramer revealed no significant effect of maternal education on birth weight of newborn. ${ }^{15}$

We found that the majority $(79.54 \%)$ of mothers had a monthly family income of $<20,000$ NRs followed by $16.3 \%$ with $20,000-40,000 \mathrm{NRs}$ income. $24.6 \%$ of lowest income group $(<20,000 \mathrm{NRs})$ mothers delivered a LBW baby. It was observed that the proportion of low birth weight decreased with increasing total monthly income of the family. Similarly, Yadav et al., found that the proportion of LBW babies decreased with increase in the per capita income of the family. ${ }^{23}$

This study showed that maximum number of mothers $142(64.5 \%)$ were from rural area. The percentage of low birth weight babies were more in mothers from rural area $(26.8 \%)$ than in mothers from urban area $(17.9 \%)$. However no association could be revealed between place of residence and birth weight of baby. Similarly, Yadav et al., found $84 \%$ mothers residing in rural areas of terai region of Nepal in which the proportion of LBW among mothers residing in rural $(21.71 \%)$ and urban $(20.83 \%)$ areas was similar. ${ }^{23}$ NDHS (2011) shows little difference in the percentage of children of low birth weight by urban-rural residence. ${ }^{21}$ Badshah et al., found area of residence significant risk factor for high incidence of SGA. ${ }^{28}$

In present study majority of mothers $(85.5 \%)$ were Hindu by religion. The relation between religion and birth weight was not significant. These findings correlated with the study done by Yadav et al., in which religion and birth weight association could not be established. ${ }^{23}$

In this study, 78 (35.45\%) belonged to nuclear family and $142(64.55 \%)$ mothers belonged to joint family. Low birth weight proportion was $23.2 \%$ among joint families, $24.4 \%$ among nuclear families. No significant association could be revealed between type of family and birth weight of baby. This was in accordance with the study done by Yadav et al., who found no association between family type and LBW.23

Likewise in this study out of 220 mothers, 192 (87.3\%) had adequate i.e. $>4$ ANC visits and $28(12.73 \%)$ had inadequate antenatal visits or no visits. The percentage of low birth weight was maximum (42.9\%) in mothers with inadequate or no visits and it decreased to $20.8 \%$ when visits were adequate. Kamaldoss did not find any significant association. ${ }^{14}$ Anand et al., ${ }^{31}$ Yilgwan et al., ${ }^{26}$ 
Roudbari et al., ${ }^{25}$ Singh et al., ${ }^{6}$ Tuladhar et al., ${ }^{34}$ and Yadav et al., ${ }^{23}$ found significant association between antenatal care and birth weight of baby. They observed that with fewer number of ANC visits or no any visit at all increased the proportion of low birth weight among them.

In our study almost all (95.45\%) respondents received iron and folic acid tablets with 95\% CI (94.60 to 96.30) but percentage of low birth weight was more $(30 \%)$ in mothers who have not consumed iron and folic acid tablets and was $23.3 \%$ in mothers who consumed iron and folic acid tablets. Whereas, Roudbari et al., ${ }^{25}$ and Rizvi et al., ${ }^{35}$ found the prevalence of LBW in mothers not using supplements such as multivitamins, iron, folic acid or calcium during pregnancy was significantly greater as compared to present study.

The proportion of low birth weight babies was high among anaemic mothers $(26.7 \%)$ than non-anaemic mothers $(22.1 \%)$ in this study. Though the relation between anaemia during pregnancy and birth weight was not found statistically significant in the present study. Other studies carried out by Anand et al., ${ }^{31}$, NDHS (2011) ${ }^{21}$, Rizvi et al., ${ }^{35}$ Badshah et al., ${ }^{28}$ Singh et al., ${ }^{6}$ and Yadav et al., ${ }^{23}$ found significant relationship between anaemia and birth weight of newborn.

In our study, LBW was $60 \%$ among mothers with height $<145 \mathrm{~cm}$ and $22.8 \%$ in $\geq 145 \mathrm{~cm}$ height mothers. As the mother's height increased further, percentage of low birth weight decreased. These findings are well supported by studies done by Yilgwan et al., ${ }^{26}$ Singh et al., ${ }^{6}$ and 10 other studies reported by $\mathrm{Kramer}^{15}$. All of them found that with increasing maternal height, birth weight of the baby decreased.

In the present study out of the total low birth weight babies, $24.2 \%$ were males and $22.8 \%$ were females. This finding correlated with the study conducted by Kayastha et al., who found $52.0 \%$ male and $48.0 \%$ female LBW babies. ${ }^{24}$ But others studies showed higher risk of LBW in female babies like Mondol found LBW in females (25.74\%) as compared to the males $(17.59 \%)$ with odds ratio of $1 .{ }^{22}$. Similarly, Yilgwan et al., ${ }^{26}$ found LBW in females $63 \%$ and male babies 37\% and Singh et al., ${ }^{6}$ found that out of total low birth weight babies $58.9 \%$ were females and $41.1 \%$ were males. Whereas, Roudbari et al., found no difference in prevalence of LBW between boys and girls $(11.1 \%$ versus $12.6 \%)^{25}$

Out of 220 mothers in this study, 114 (51.82\%) mothers had received rest ( $\geq 2$ hours) in the afternoon during pregnancy whereas $106(48.18 \%)$ mothers had received $<2$ hours of afternoon rest with $95 \%$ CI (46.15 to 50.21 ).
The percentage of low birth weight was high $(34 \%)$ in mothers who had received $<2$ hours rest in afternoon as compared to mothers who had received $\geq 2$ hours rest $(14 \%)$. A significant association was found between rest received in afternoon during pregnancy and birth weight of baby (p-value $<0.05$ ). Those who took $<2$ hours rest in the afternoon have higher odds of low birth weight as compared to rest received $\geq 2$ hours in the afternoon $(\mathrm{OR}=2.446$, with $95 \%$ CI 1.156 to 5.178). This result was found to be statistically significant ( $\mathrm{p}$-value $=0.019$ ). Similarly, Yadav et al., also found significance between mid day rest during pregnancy and LBW as out of mothers who had no mid day rest during their pregnancy $44 \%$ mothers delivered LBW babies. ${ }^{23}$

The percentage of low birth weight in our study was maximum among $(43.1 \%)$ mothers who were taking diet less than or same as before during their pregnancy and LBW was less (16.7\%) among those who were taking diet more than before. A significant association was found between diet intake during pregnancy and birth weight of baby ( $\mathrm{p}$-value $<0.05$ ). Also mothers who took the dietary intake same or less than before during pregnancy have higher odds as compared to dietary intake more than before $(\mathrm{OR}=3.441$, with $95 \%$ CI 1.599 to 7.405$)$. This result was also found to be statistically significant ( $\mathrm{p}$-value $=0.002$ ). Idris et al., ${ }^{4}$ Sachar et al., ${ }^{36}$ and Yadav et al., ${ }^{23}$ also found a significant association between nutrition during pregnancy and low birth weight similar to present study. The incidence of LBW was $37.4 \%, 23.3 \%$ and $55 \%$ respectively among those taking no additional or inadequate diet during pregnancy in these studies. Rizvi et al., ${ }^{35}$ and Singh et al., ${ }^{6}$ found that with increase in maternal post-partum weight, risk of LBW decreased.

In the present study $20.90 \%$ of the respondents had preterm delivery (with 95\% CI 19.25 to $22.55 \%$ ) and proportion of low birth was high among pre-term babies $(60.9 \%)$ than term babies $(13.8 \%)$. A significant relation was seen between gestational age of pregnancy and birth weight(p-value $<0.05)$. The odds of low birth weight children were higher among those mothers who had preterm deliveries ( $\mathrm{OR}=9.078$, with $95 \%$ CI 4.148 to 19.869), this result was found to be statistically significant $(\mathrm{p}$-value $=<0.001)$. Similarly, Badshah et al., also found preterm deliveries $(22.8 \%)$ with higher LBW proportion $(26.2 \%)$ and higher odds $(\mathrm{OR}=6.4$, with $95 \%$ CI 4.1 to 9.8) than full term deliveries with statistically significant association. ${ }^{28} \mathrm{Mondol}^{22}$, Yilgwan et al., ${ }^{26}$ Kayastha et al., ${ }^{24}$ and Khorshidi et al., ${ }^{27}$ all found that mothers with preterm deliveries were at a higher risk for having LBW babies as compared to those with full-term deliveries. So, gestational age was found to be significant risk factor for high incidence of LBW like the present study. 
Also in this study the Pseudo R-square revealed that the value are 0.229 and 0.334 respectively, suggesting that variation in low birth weight was seen between $22.9 \%$ and $34.4 \%$ in relation to three risk factors i.e rest received in the afternoon during pregnancy, dietary intake during pregnancy and period of gestation which were used in the model. These risk factors showed strong association with low birth weight.

\section{Limitations}

This study was conducted only among institutional deliveries, so these findings cannot be truly representative of entire population.

\section{CONCLUSION}

The prevalence of low birth weight was found to be significantly high among institutional deliveries of this region of the country. Socio-cultural and maternal risk factors like rest received in the afternoon during pregnancy, dietary intake during pregnancy and period of gestation were found to be significantly associated with low birth weight babies. The problem of low birth weight babies can thus be lessened down as most of these factors can be tackled easily by providing adequate and effective antenatal care as well as home care. Also emphasis should be given that large number of mothers utilise the available antenatal care services at utmost level. Unless this problem is tackled infant and child mortality rates cannot be brought down. Cost effective alternative measures is required to enhance female literacy, as illiteracy is directly related to low socio-economic condition, poor nutrition, lack of rest and underutilisation of services. Hence the problem of low birth weight babies was found to be prevalent and associated with various risk factors resulting in its continual endemicity in newborns.

\section{ACKNOWLEDGEMENT}

We would like to thank all the respondents enrolled in the study for their co-operation.

\section{REFERENCES}

1. Park K. Preventive medicine in obstetrics, paediatrics and geriatrics, Nutrition and health. In: Park's text book of preventive and social medicine. $20^{\text {th }}$ ed. Jabalpur: Bhanot; 2009. p. 451-596.

2. WHO: Programs and Projects. Nutrition. Feto-maternal nutrition and low birth weight. Development of a strategy towards promoting optimal fetal growth.http://www.who.int/entity/nutrition/ topics/feto_maternal/en/(2013). Accessed 21 April 2013.

3. Puffer RR and Serrano CV. Patterns of birth-weights. Pan American Health Organization Scientific Publication. 1987; 504:109.
4. Idris MZ, Gupta A and Mohan U. Maternal Health and low birth weight among institutional deliveries. Indian Journal of Community Medicine 2000;25(4):156-160.

5. Institute of Health Economics. Determinants and Prevention of Low Birth Weight: A Synopsis of the Evidence.2008. http://www. ine.ca/publications/library/2008/determinants-and-preventionof-low/. Accessed 21 April 2013.

6. Singh SD, Shrestha S and Marahatta SB. Incidence and risk factors of low birth weight babies born in Dhulikhel Hospital. Journal of Institute of Medicine 2010; 32(3):39-42.

7. Child Trends Data Bank. Low and very low Birth weight Infants: Indicators of child and youth well-being.2012.http://www. childtrendsdatabank.org/. Accessed 21 April 2013.

8. Department of Health Services. Annual Report. Ministry of Health and Population. Government of Nepal. 2073/74 (2016/2017), 2018. p. 32.

9. UNICEF. Situation of Children and Women in Nepal. Kathmandu, Nepal; 2006.

10. Department of Health Services. Annual Report. Ministry of Health and Population. Government of Nepal. 2056/66(2008/2009), 2010. p. 43-106.

11. Ghosh S, Bhargava SK, Saxena HM and Sagreiya K. Perinatal mortality: report of a hospital-based study. Annals of Tropical Paediatrics 1983;3(3):115-119.

12. Moore KL. Before we are born: basic embryology and birth defects. Toronto: Saunders; 1983.

13. Population Division. Nepal Demographic and Health Survey. Ministry of Health and Population, Government of Nepal. 2006, 2007. p.127-194.

14. Kamaladoss $T$, Abel $R$ and Sampathkumar V. Epidemiological co-relates of low birth weight in rural Tamil Nadu. Indian Journal of Paediatrics 1992;59(3):299-304.

15. Kramer MS. Determinants of low birth weight: methodological assessment and meta-analysis. Bulletinof the World Health Organisation 1987; 65(5):663-737.

16. Bale JR, Stoll BJ and Lucas AO. Improving birth outcomes: meeting the challenge in the developing world. Institute of Medicine of the National Academics. The National Academies Press: Washington, DC. 2003. p. 207.

17. Subcommittee on Nutrition. The world nutrition situation: nutrition throughout the life cycle. United Nations Administrative Committee on Coordination. Report number: 4, 2000.

18. Allen LH and Gillespie SR. What works? A review of the efficacy and effectiveness of nutrition interventions. United Nations Administrative Committee on Coordination Subcommittee on Nutrition. 2001.

19. Bhargava SK, Sachdev HS, Fall CHD, Osmond C, Lakshmy R, Barker DJP, et al. Relation of serial changes in childhood body mass index to impaired glucose tolerance in young adulthood. New England Journal of Medicine 2004; 350(9):865-875.

20. UNICEF. The State of World's Children 2009. Maternal and Newborn Health. 2008. p.2-15.

21. Population Division. Nepal Demographic and Health Survey. Ministry of Health and Population, Government of Nepal. 2011, 2012; 148-149.

22. Mondol B. Risk factors for low birth weight in Nepali infants. Indian Journal of Paediatrics. 2000; 67(7):477-482.

23. Yadav DK, Chaudhary $U$ and Shrestha N. Risk factors associated with low birth weight. Journal of Nepal Health Research Council 2011;9(19):159-164.

24. Kayastha $\mathrm{S}$ and Tuladhar $\mathrm{H}$. Study of low birth weight babies in Nepal Medical College. Nepal Medical College Journal 2007; 9(4):266-269. 
25. Roudbari $M$, Yaghmaei $M$ and Soheili $M$. Prevalence and risk factors of low birth weight infants in Zahedan, Islamic Republic of Iran. Eastern Mediterranean Health Journal 2007;13(4):838-845.

26. Yilgwan CS, Abok II, Yinnang WD and Vijima BA. Prevalence and risk factors of low birth weight in Jos. Jos Journal of Medicine 2009;doi:10.4314/jjm.v4i1.55095.

27. Khorshidi M, Nooshirvanpour P and Najafi S. Incidence of Low birth weight in Mazandaran Province, Northern Iran. Oman Medical Journal 2013; 28:(1):39-41.

28. Badshah S, Mason L and McKelvie K. Risk factors for low birthweight in the public-hospitals at Peshawar, NWFP-Pakistan. BMC Public Health 2008, 8:197.

29. Panaretto $K$, Lee $H$, Mitchell $M$, Larkins $S$, Manessis $V$, Buettner $\mathrm{P}$, et al. Risk factors for preterm, low birth weight and small for gestational age birth in urban Aboriginal and Torres Strait Islander women in Townsville. Aust NZJ Public Health 2006;30(2):163-170.

30. Rana SS. Effect of maternal age on fetal weight. Medical Journal of Shree Birendra Hospital. 2011; 10(2):15-17.
31. Anand K and Garg BS. A study of factors affecting low birth weight. Indian Journal of Community Medicine 2000; 25(2):57-62.

32. Ezechi OC, Kalu BKE, Ndububa, Loto OM, Ezeobi PM1 and Nwokoro CA. Obstetric performance in elderly Nigerian women: a comparative study. Nepal Journal of Obstetrics and Gynaecology 2007;2(1):9-12.

33. Joshi SM and Pai NP. Effect of maternal biosocial determinants on the birth weight in a slum area of Greater Mumbai. Indian Journal of Community Medicine 2000; 25(3):121-124.

34. Tuladhar $\mathrm{H}$ and Dhakal $\mathrm{N}$. Impact of antenatal care on maternal and perinatal outcome: a study at Nepal Medical College Teaching Hospital. Nepal Journal Of Obstetrics and Gynaecology 2011; 6(2):37-43.

35. Rizvi SA, Hathcher J, Jehan I and Qureshi R. Maternal risk factors associated with low birth weight in Karanchi: a case control study. Eastern Mediterranean Health Journal 2007;13(6): 1343-1344.

36. Sachar RK, Kaur N, Soni RK, Dhot R and Singh H. Energy consumption during pregnancy and its relation to birth weight: a population based study from rural Punjab. Indian Journal of Community Medicine 2000;25(4):166-169.

\section{Authors Contribution:}

PB- Concept and design of the study, reviewed the literature, collected data, statistically analyzed and interpreted, preparation of manuscript and critical revision of the manuscript; SG-Concept and design of the study, helped in collection of data, critical revision of manuscript and review of the study; HPU- statistically analyzed and interpreted the data.

Orcid ID:

Dr. Prerna Bansal - iohttps://orcid.org/0000-0001-7876-6637

Dr.Sandeep Garg - Dhttps://orcid.org/0000-0002-5425-9494

Mr. Hari Prasad Upadhyay - ohttps://orcid.org/0000-0003-4422-4842

Source of Support: Nil, Conflict of Interest: None 